\title{
Effectiveness of Concept Mapping Based Teaching Methods on Grade Eight Students' Conceptual Understanding of Photosynthesis at Ewket Fana Primary School, Bahir Dar, Ethiopia
}

\author{
Yenenesh Workneh Woldeamanuel ${ }^{1}$, Nega Tassie Abate ${ }^{1 *}$, Dessalegn Ejigu Berhane ${ }^{1}$ \\ ${ }^{1}$ Bahir Dar University, College of Science, Department of Biology, Bahir Dar, ETHIOPIA
}

Received 10 June 2020 - Accepted 20 September 2020

\begin{abstract}
Concept mapping helps learners to understand complex ideas. However, studies confirming that statement are scarce. A quasi-experimental and Design-based approaches were applied to understand the effectiveness of concept mapping based teaching method on grade eight students' conceptual understanding of photosynthesis. Two sections of grade eight consisting of 103 students were selected randomly. Pretest results were used to assign students as experimental and control groups and treated with concept mapping and lecture methods, respectively. The post-test results of the two study groups revealed a statistically significant difference indicated that students' treated with concept mapping method exhibited better conceptual understanding on the concept of photosynthesis than those treated with lecture method. This study suggests that science teachers should apply concept mapping method to teach science concepts systematically. The use of concept mapping method in science classes can help students to better understand the important concepts.
\end{abstract}

Keywords: concept mapping, photosynthesis, quasi-experimental design, lecture method, Ethiopia

\section{INTRODUCTION}

One of the most important goals of education is to foster students in becoming learners who possess the cognitive learning strategies to acquire a conceptual understanding of the subject matter (Trifone, 2006). Learning strategies serve to aid the learner in encoding information and thus affect learning outcome and performance. It is a means of understanding of fundamental concepts, relationship between concepts and applying of concepts into practice to solve problems (Darmofal et al., 2002).

Conceptual understanding requires clarification of misconceptions and offers the potential to engaging students in the teaching-learning process. Therefore, the learner requires a deliberate effort to relate new knowledge to relevant concepts that they already possess in their mind (Sequeira, 2012). So this study focused on developing students' conceptual understanding in their learning of photosynthesis, a biological process that reduces carbon dioxide to carbohydrate.

Understanding the mechanisms and principles underlying biological robustness is necessary for an indepth understanding of biology at the system level (Csete \& Doyle, 2002). many concepts or topics in biology including water transport in plants, protein synthesis, respiration and photosynthesis, gas exchange, energy, cells, genetics, organs and central nervous system can be perceived as difficulties to learn and understand by students (Fauzi \& Mitalistiani, 2018). Some of the reasons for students' difficulty in learning and understanding of these biological concepts include, the subject itself involves many abstract and complex relationships between and among many concepts, the overloaded biology curricula and lack of teachers' pedagogical knowledge in teaching-learning process (Cimer, 2012).

Photosynthesis is the most important biochemical process on Earth that most living things depend on it directly or indirectly. Knowledge about photosynthesis 


\section{Contribution to the literature}

- This paper employs the quasi experimental design to understand the effectiveness of CM based teaching method on grade eight students' conceptual understanding of photosynthesis.

- This paper will help all elementary school science teachers to apply CM method to teach science concepts systematically.

- The use of CM method in science classes can help students not only to better understand the important concepts but also to construct knowledge bases.

- This paper will help science teachers to apply CM method in teaching of complex and abstract concepts.

- $\mathrm{CM}$ is one of the constructive approaches that promote an active teaching-learning environment.

- This study will lead teachers and students to integrate technology in science education.

- Interestingly, Ethiopian Ministry of education might use the study to incorporate CM technique in the curricula of science education.

enables us to understand how the world functions as an ecosystem and how photosynthesis acts as a bridge between the non-living and living worlds (Dimec \& Strgar, 2017). This important biochemical process is dealt throughout the school curriculum with the most emphasis in science courses particularly in Biology.

Most school teachers favored traditional teaching approach for teaching biology concepts which rewards learners' ability to reproduce facts without truly understanding the topic and predictably fails in the face of complex interactions involved in biology (Schmid \& Telaro, 2018). In traditional teaching method teachers teach students' mostly using chalk and talk technique, teachers write notes on the black board and students just copy on their notebook and this leads to an overloading of information on students. This method is useful for teachers to teach their subject easily and to cover the course in time. However, this does not motivate students in their learning to construct knowledge and to understand scientific concepts systematically (Bahar, 2010; Shamsudin, 2014).

Therefore, students' difficulties with many topics in biology have stimulated researchers to investigate why students experience such difficulties and how to overcome these difficulties. Consequently, various teaching-learning strategies which evolve from the learning theories have been developed to accelerate learning process of students in science. For example, a paradigm shift from the behaviorism to constructivism enhances conceptual learning and development of attitude towards science (Irez \& Han, 2011). One of the much heralded of the paradigm shift from teachercentered instruction to student-centered instruction approach to biology teaching is constructivism (Jia, 2010).

Constructivist theory is one of the contemporary learning theories that emerged from the philosophical basis that the teacher's role should be trainer, facilitator of learning processes and creator of convenient educational environments. Constructivist presents a view of learning that is particularly useful in describing conceptual learning and belief that individuals can actively construct their knowledge through testing concepts on prior experience by applying these concepts to new situations (Darmofal et al., 2002). Constructivist learning theory also argues that new knowledge should be integrated into existing structures in order to be remembered and receive meaning.

Concept mapping (CM) is one of the constructivism approaches derived from meaningful learning theory and ideally suited to teach and address biological concepts (Schmid \& Telaro, 2018). This study chooses this constructive teaching approach to see its effectiveness on evaluating students understanding on photosynthesis concepts. This is because as described by Tekkaya et al. (2001) photosynthesis one of the difficult concepts in biology that involves many abstract and complex natural relationships. $\mathrm{CM}$ is one of the new teaching styles that enable learners to connect all information in their mind and it has been widely recommended in science education because it enables learners to better remember and learn information both visually and verbally (Cheema \& Mirza, 2013). It is also a teaching-learning strategy that helps learners in understanding of complex ideas and clarifies ambiguous relationships among ideas (Ajaja, 2011; Shamsudin, 2014).

Often $\mathrm{CM}$ bears a similarity to the structure of longterm memory. However, instead of describing all concepts and their relations in text, it is important to choose a map indicating concepts and relations in a graph or network form because graphical form allows representations of parts and whole in a way that is not available in sequential structure of a text (Asan, 2007). Unlike the teacher centered traditional teaching approach, CM allows students to think deeply about science by helping them to better understand and organize what they learn, and to store and retrieve information more efficiently. In addition, CM serves teachers to examine how well a student understands science by observing and analyzing the sophistication of their concept maps (Asan, 2007).

Therefore, based on the literatures and teacherresearcher experience most of the time teachers apply 
traditional-teaching method particularly lecture based method. One of the main reasons for applying this method of teaching is due to lack of pedagogical knowledge to deliver the concept of the subject for students. Lecture based method of teaching using chalk and talk rewards students to reproduce facts without truly understanding the topic and predictably students fail in the face of complex interactions of concepts and make students to have misunderstandings on science concepts. The choice of relevant teaching method and students' difficulties in understanding science concepts are the core reasons to conduct this study. Therefore, this study attempts to understand the effectiveness of $\mathrm{CM}$ based teaching method on students' conceptual understanding of photosynthesis in grade eight biology classes at Ewuket Fana Primary School, Bahir Dar, Ethiopia.

\section{LITERATURE REVIEW}

\section{Students' Misconceptions about Photosynthesis}

Students mostly held misconceptions on determining time when photosynthesis occurred, location of photosynthesis occurred, raw materials needed for photosynthesis, products resulted from photosynthesis and also they think that plants get food from the soi1, and water and minerals taken in from the soil are sources of the plants "food" (Galvin et al., 2015). Similarly Dimec and Strgar (2017) described the common misconceptions which are held by students such as plants get their food from their environment, especially from the soil, roots are the organs of feeding, plants have multiple sources of food, sunlight absorbed by plants is food and photosynthesis is something that plants do to the benefit of people and animals, particularly in relation to the exchange of gasses. Besides, Maramroti and Galanopoulus (2006) described that students do not understand energy transformations and the role of chlorophyll in photosynthesis; they do not see photosynthesis as a chemical reaction; they think plants receive food from their environment, and they are confused about photosynthesis and respiration.

\section{Concept Mapping}

CMs are often constructed with reference to some particular question we seek to answer, which is called a focus question. It is the process of creating visual representation of knowledge that humans organize and communicate information. It is a general and an active teaching-learning strategy that can be used to help any individual or group to describe their ideas about some topic in a pictorial form. This method of representing of ideas is used to give a relationship between and among concepts, and identifies how they relate each other (Schwendimann, 2015).
For many years CM has been constructed by hands using paper-pencil or chalk-board. But later the development of personal computer enabled the development of software programs that facilitated the construction of CMs and evolved into the current version of concept mapping tools (Novak \& Canas, 2006). Nowadays, software supported CM tools are popular in schools, universities and governmental and non-governmental agencies. These tools are better than paper-pencil and chalk-board CM method because they allow the user to readily rearrange concepts and links to restructure the maps, and they help to link different sources such as photos, videos, graphs and notes to create graphical nodes representing concepts, and to connect nodes using lines and linking words to form a network of interrelated propositions that represent knowledge of a topic (Jena, 2012).

\section{Development of Concept Map}

Novak and his research team at Cornell University developed $\mathrm{CM}$ as an instructional method to assist students with science lessons in the 1970s. This is based on Ausubel (2011) learning theory which states that learning takes place by the assimilation of new concepts and propositions into existing concept and propositional frameworks held by the learner. Hence, this knowledge structure as held by a learner is also referred to as the individual's cognitive structure. Novak and his team members have searched more manageable method for recording patterns of children's understanding of science concepts and this led to the development of concept map (Kinchin et al., 2000). Novak followed Ausubel's idea regarding cognitive structure to translate numerous interviews transcript into hierarchical organization of concepts and this organizational tool Novak used to summarize children interviews was developed to CM. Novak studied CMs and their benefits from elementary school to higher education, and he realized that $\mathrm{CM}$ is a powerful and concise knowledge representation tool to organize and understand interconnection of concepts.

\section{Instructional Concept Maps (ICM)}

The technique of representing knowledge consists of network of concepts which include nodes and links. The nodes are the concepts which are connected through links (words) to form meaning of propositions (statements). The concepts are usually enclosed in circle or box and relationships between concepts or propositions, indicated by a connecting line between two concepts. The propositions contain two or more concepts connected with other words to form a meaningful statement (Jacobs-Lawson \& Hershey, 2002). Concept mapping shows the key concepts and propositions in explicit and concise words and the superordinatesubordinate relationship between key concepts and propositions in graphs. Therefore, CM provides better 
idea about how to sequence learning materials for presentation (Galvin et al., 2015). It has an implication on students to acquire cognitive understanding of knowledge of subjects and concepts, and also a mastery of the skills for their private studies in science (Kinchin, 2001; Rahman \& Islamia, 2015).

The results quasi-experimental studies conducted by Birbili and Lin (2001) on investigating the effectiveness of CM instructional method on students' performance and understanding of science subjects including biology, physics and chemistry at early childhood education indicated, students who are exposed with CM instructional methods have better performance and understanding of the lessons than those exposed with traditional instructional methods. Similarly, Cheema \& Mirza, 2013 conducted an empirical study on the effect of CM instructional method on academic achievement of grade $7^{\text {th }}$ students in general science subjects in Sargodha city. Based on the achievement test developed by these researchers students who were taught with $\mathrm{CM}$ instructional method have better performance in the achievement test than those who were taught with a traditional method. CM instructional method is also effective to apply on slow learners. A quasi experimental study conducted by Udeani and Okafor (2012) on secondary school biology slow learner students at Enugu State in southeastern Nigeria indicate that these students perform better when they are taught with $\mathrm{CM}$ instructional methods than traditional instructional method on photosynthesis.

However, Adlaon (2012) shown in his study that students who taught with CM method did not score significantly than those who taught with traditional teaching method at the post-test result on the concept of balancing nature in high school biology. As this researcher described in his study, the possible reasons for this were students' frustrations in CM activities, less involvement of students in CM activities and teacher constructed $\mathrm{CM}$ rather than student during the learning progress.

\section{Educational Applications of CMs}

Information is processed and stored in the mind of children in linguistic, visual and in a complex set of interrelated memory systems. All incoming information is organized and processed in the working memory by interaction with knowledge in long-term memory (Birbili \& Lin, 2001). Although the structure must be built up piece by piece with small units of interacting concept and propositional frameworks, CM serves as a kind of template or scaffold to help organize knowledge and structure it. Once children learn how to read and make $\mathrm{CM}$, it is easy for teachers to identify their prior knowledge as well as misconception and use it as an assessment tool (Birbili \& Lin, 2001; Cook, 2017).

\section{Concept Teaching and Learning}

Concepts in any subject are the basic building blocks for higher-level thinking. Without understanding concepts, there is no comprehension and cognitive development. They are bodies of knowledge or the mental representation that people have about entities in the world that stored in their memory and used in the process related to higher capacities (Kokkonen, 2017). In teaching and learning of any science subject, concepts do not exist in isolation instead interrelate for meaning (Stoica et. al, 2011).

However, many students have difficulties in identifying the main concept of the topics in text, lecture and other forms of presentation. The problem comes from the methods of learning that simply required memorization of information but not required evaluation. Such students fail to understand concepts and leading them to see learning as a blur of myriad facts or procedural rules to be memorized (Jibrin \& Zayum, 2012). For such students the subject matter of most disciplines is a cacophony of information to memorize, and they usually find this boring. Thus, $\mathrm{CM}$ has been explored as learning tool in a wide range of science disciplines including chemistry, biology, physics, earth science, ecology, astronomy, and medicine (Schwendimann, 2015). Instructional CMs are flexible tools that can be used in a variety of educational settings including knowledge construction, meaningful learning, assessment evaluation of students understanding and misconceptions, and instructional planning (Adlaon, 2012).

\section{METHODOLOGY}

\section{Design of the Study}

The study used design based research which involves the development of interventions/applying of the teaching strategies in the process (Figure 1) and quasiexperimental research designs/taking of two groups for the study (Table 1). The present study has both experimental and control groups. Before the instruction both experimental and control groups assigned to take pre-test on the concept of photosynthesis and its related concepts. During the instruction, students in the experimental group were exposed to concept mapping based learning for three weeks on the concept of photosynthesis and its related concepts. Students constructed $\mathrm{CMs}$ in groups during and after the instruction and explained their maps to the class, and after the students constructed and explained their maps, finally they were given computer based reference CMs, some pictures and videos related to photosynthesis by attaching to the CMs. Whereas students in control group were exposed to traditional (teacher-centered) teaching method. In addition to the pre and post-tests, classroom observation and informal assessment activities were also 




Figure 1. Procedures of Design-based research approach

Table 1. Design of quasi-experimental study approach

\begin{tabular}{llccc}
\hline Group & Selection & Evaluation I & Treatment & Evaluation II \\
\hline Experimental & Purposive & Pretest & CM & Post-test \\
Control & Purposive & Pretest & Lecture & Post-test \\
\hline
\end{tabular}

Table 2. The groups and number of students involved during pre-test and post-test

\begin{tabular}{lccc|ccc}
\hline \multicolumn{9}{c}{ Number of students } \\
\hline Group & Male & Pre-test & & & Post-test & \\
\hline Experimental & 15 & 38 & Total & Male & Female & Total \\
Control & 18 & 32 & 53 & 15 & 38 & 53 \\
Total & 33 & 70 & 103 & 15 & 32 & 47 \\
\hline
\end{tabular}

conducted in both groups before, during, and after instruction. This is to support and triangulate the data. At the end of the lesson, students in both groups were assigned to take post-test about of photosynthesis and related concepts.

\section{Sample}

A total of 103 students, from the two sections of grade $8^{\text {th }}$ were attending the lesson about photosynthesis by the same teacher. The two sections were randomly selected out of four sections of grade eight from Ewket Fana Primary School, Bahir Dar, the capital of Amhara National Regional State (ANRS), Ethiopia. These sections were assigned as experimental and control groups based on students' pre-test result (Table 2).

\section{Data Gathering Instruments}

Biology achievement test, informal assessment questions, classroom observation of students' activities and $\mathrm{CM}$ activities in experimental group were used to gather data in this study. The tests were two in type, multiple choices about photosynthesis and its related concepts and matching the parts of plants with their functions. These tests were administered two times; at the beginning of the study to measure the equivalence of the two groups' prior knowledge on photosynthesis to determine the control and experimental groups. The second test was administered at the end of the intervention period.

The informal assessments were conducted by delivering open-ended questions before, during, and after intervention in every day lesson to measure students thinking about photosynthesis, to determine what students know about the role of photosynthesis in global warming, and to identify students' knowledge about the role of light for photosynthesis.

Self-observation was also carried out in everyday intervention to measure students' interaction towards the instructional methods following their activities during the intervention periods. This is to measure the participation of students in their learning, interaction with the teaching material, interaction among the groups, students' interest towards the instructional method and students' ability to answer by relating concepts into their daily life experience. These observation measurement activities are developed based on the teacher researcher own experiences in teaching and learning process. When these self-observations were designed, the researcher prepared the lesson plan to teach the concept of photosynthesis and these selfobservations were related to the lesson plan, so all of these activities were followed by the advisor together with the school principal and the school biology teachers during the daily intervention process.

The assessment questions applied for pre and posttests and for informal assessment were adapted from the study of Dimec and Strgar (2017) which concentrated on students' misunderstanding on photosynthesis concepts. Data triangulation helps to increase confidence in research data and the validity of a study (Thurmond, 2001). In this study stakeholders such as school biology teachers, school administrators and colleagues in the same field were used to triangulate the qualitative and quantitative data to gain insight on the outcomes of applying the $\mathrm{CM}$ on acquiring meaningful leaning about the concept of photosynthesis. The stakeholders responses were examined to determine the level of agreement and divergence on the data the researcher achieved by providing structured questions to evaluate 
the performance of students while conducting pre- and post-observations. The above mentioned stakeholders were given the same observation checklist for pre- and post-observations, and after analysis, validity was established for the level of students conceptual understanding that were identified by observers. The data were analyzed quantitatively through descriptive and inferential statistics (t-tests), and qualitatively through narration. The data that gathered based on the pre and post-tests were analyzed statistically using quantitative method whereas the data gathered based on class room observation and informal assessment were explained qualitatively in words.

\section{Intervention}

This study was conducted for three weeks in the second semester of 2011 academic year. The researcher here acts as both a teacher and a researcher. That means the teaching learning process also conducted by the researcher. The teacher researcher took two groups (experimental and control) of students. In the experimental group the students exposed to CM based teaching method while in control group they were exposed to traditional teaching method (teachercentered method) in teaching the concept of photosynthesis. The lesson was given regularly three periods in a week. The teacher researcher used a hierarchical type of $\mathrm{CM}$ by giving priority to the most general concepts at the top of the map and sub-concepts at the bottom. This is based on meaningful learning theory that stated concepts are arranged in long term memory in hierarchical maps.

In the experimental group students with different learning abilities were arranged into nine groups that consisted of six members in each. This group arrangement is made by asking the classroom biology teacher about students' abilities in their learning. This mixing group arrangement enabled students to learn, share and communicate ideas during the learning process. Students were taught the concept photosynthesis with CM based teaching method with active involvement in concept mapping activities. Prior to the intervention, pre-test questions related to photosynthesis were given to examine students' prior knowledge and misconception about the photosynthesis and its related concepts.

In the first period, questions were first raised to students about the teaching method used by their teacher during biology class and what is their attitude towards this method. Then after, they were introduced about CM method and explained why CM is a useful tool for learning and how concept mapping can be used to show relationships among concepts, and the steps to be used in this study to implement CM based teaching method; the steps included in this study were: provided focused questions, allowing students to read their text books and underline the main concepts from the text, listing of all concepts on the paper and discussion, arrangement of concepts from general to specific and relating concepts using link words. Following these, 50 minutes was spent to train students regarding the implementation of $\mathrm{CM}$ as a teaching method using example.

CMs were prepared by teacher researcher for the purpose of teaching photosynthesis and its related concepts. Besides, computer assisted CM tool IHMC (institution for human machine and cognition) was used to prepare CMs for each sub-lessons of photosynthesis. The computer assisted CMs were prepared mainly to teach the concept of photosynthesis from the text in visual and explicit form. However, students used paperpencil and chalk- board to constructed CM rather than computer assisted software due to lack of technological resources in the study area, shortage of time to use computer based CM activities, and lack of students computer skill, instead after students had constructed and presented their CMs, they got the computer assisted reference CMs in print form for cross checking their maps, to examine the relationship between and among concept and for their study of the topic photosynthesis.

Before students introduced into each daily lessons, pre-informal assessment open ended questions were asked and allowed students to reflect their answers. These questions were considered as pre informal assessment and they helped to identify students' conception on the concept of photosynthesis in addition to the pre-test questions. After students understanding and misunderstanding were identified on the questions, they got introduced the daily lessons, objectives and the teaching process were began. Again these open-ended informal assessment questions were given after interventions to see at what extent the CM based teaching method can develop students understanding.

In the first week of the teaching-learning process, students had given focused questions and list of concepts related to the daily lessons; they made discussion on the given question by relating the given listed concepts using their prior experience and knowledge and presented their discussion in the class room. After students understanding and misunderstanding were identified, they were exposed to computer assisted reference CMs that depicted and described the daily topics. Following this, students were observed to examine whether they understood the map and the relation of concepts. At the same day another focused set questions were prepared and given to students as homework for the next period to practice identifying the main concepts related to the daily topics and to adapt the CM method. For example, in the first week of interventions students were given focused questions about pants (what are plants?) and their related concepts (such as livening things, multicellular organisms, autotrophs, chloroplast, photosynthetic 
Table 3. The t-test results of biology achievement pre-test scores for control and experimental groups

\begin{tabular}{lcccccc}
\hline Group & $\mathrm{N}$ & Mean & Std. deviation & $\mathrm{p}$ & $\mathrm{df}$ & $\mathrm{T}$ \\
\hline Experimental & 53 & 3.73 & 2.25 & \multirow{2}{*}{60} & \multirow{2}{*}{101} & \multirow{2}{*}{.53} \\
Control & 50 & 3.94 & 1.80 & & \\
\hline
\end{tabular}

Table 4. The t-test results of biology achievement post-test scores for control and experimental groups

\begin{tabular}{lccccccc}
\hline Group & Test & $\mathrm{N}$ & Mean & Std. deviation & $\mathrm{df}$ & $\mathrm{t}$ & $\mathrm{p}$ \\
\hline Experimental & $15 \%$ & 53 & 10.42 & 2.08 & \multirow{2}{*}{86.58} & \multirow{2}{*}{7.41} & \multirow{2}{*}{0.00} \\
Control & $15 \%$ & 50 & 7.92 & 1.26 & & & \\
\hline
\end{tabular}

organisms, chlorophyll, light energy, photosynthesis) to aware them about the general characteristics of plants and also to introduce the concept of food manufacturing by green plants.

Here, students discussed on the question through relating the given listed concepts, scaffolded by the researcher, they were allowed to relate those listed concepts with the main topic "plant" by constructing their own CMs and finally students present their discussion about plants in the class room by showing their map on the black board. Following this, students were observed to examine whether they understand the map and the relation of concepts of plants. At the same day another focused question (importance of plants) was prepared and given to students as homework for the next period to explain the importance of plants through constructing their own CM using the listed provided concepts. The same procedures were carried out for the succeeding lessons in the first week. Generally, students in the first week of intervention practice constructed CM using concepts list provided. They were also given blank spaced CMs to practice them in CM method.

In the second and third weeks open ended focusing questions relating to the topics were given for students. Students were allowed to read, identify, list and discuss the main concepts from the textbook. Students then constructed their own CMs, connect the selected concepts using arrows and link words and form propositions on the paper and their notebooks, discussed their maps within group and shared ideas. Right after, students were allowed to present their CMs to the class by drawing on the black board. After students understanding and misunderstanding were identified from their map, they were exposed to computer assisted reference CMs. Then students identify their misconception (if any) and follow up the explanation, correct their CMs accordingly. The same procedures were followed for the succeeding lessons in the second and third weeks. At the end of the topic photosynthesis, experimental group students were asked to construct CM using paper and pencil to explain what they had learned and understood about photosynthesis. This helped to understand students' ability of relating concepts through constructing their own CMs. Later, students' CMs were discussed and compared with computer assisted reference CMs to evaluate the level of understanding of students in relating photosynthesis concepts.

However, students in control group were taught the concept of photosynthesis with traditional based teaching method specifically using lecture method. Students in this group sited normally without any group arrangement. There is no any concept mapping activities. During the first period introductory lessons and plans on how to deliver the lessons were given. Until the end of the lessons students were taught the concept of photosynthesis followed by introduction, presentation, summarization and evaluation of the lessons. The implementation periods were the same as the experimental group.

\section{RESULTS}

\section{Results from Pre-test and Post-test}

Before the intervention, a photosynthesis concept test was given for both groups as pre-test. The result of the pre-test showed that for experimental group the average score was 3.73 . While for control group the average score was 3.94 (Table 3).

The results in Table 3 showed that there was no significant mean difference between experimental $(\mathrm{M}=$ $3.73, \mathrm{SD}=2.25)$ and control groups $(\mathrm{M}=3.94, \mathrm{SD}=1.80)$ on their biology achievement test success $(t)(101)=0.53$, $p=0.60)$. This suggested that the two groups had equivalent prior knowledge and understanding on the concept of photosynthesis before the intervention. This is suitable for this study because the two groups have comparable characteristics. After intervention, the control and experimental group students were given the photosynthesis concept tests again as a post-test. This test was used to answer the question "does concept mapping based teaching method improve students' conceptual understanding of photosynthesis?" Based on the result, the average scores of experimental and control groups in posttest were 10.42 and 7.92, respectively (Table 4).

As results in Table 4 showed students in both groups scored better result after the treatment. However, the mean post-test score for experimental group $(\mathrm{M}=10.42$, $\mathrm{SD}=2.08)$ was higher than the control group $(\mathrm{M}=7.92$, $\mathrm{SD}=1.26), \mathrm{t}(86.58)=7.41, \mathrm{p}=0.00$. That means students who were taught with CM method had improved their 
test scores and understood the concept of photosynthesis better than those taught with traditional (lecturing) method.

\section{Results from Informal Assessments}

\section{Result from pre-informal assessment questions}

This study conducted informal assessment before, during, and after intervention to examine students understanding and misunderstanding of concepts related to photosynthesis by raising a question "does concept mapping based teaching method improve students' conceptual understanding of photosynthesis? As results from the informal assessment indicated most of those students' responses in both groups falls into the same ideas on the pre-informal assessment questions related to the concept of photosynthesis. For instance, the first question was how plants make their own food? Students' reflection for this question is "plants can make their food by using soil, light and water". This response indicated that students have an idea that plants can make their own food but have no detailed understanding about the process of photosynthesis that how soil, light and water are involved.

For the second question; what is the concept of photosynthesis? Students answered that "Photosynthesis is the process of making food in plants". Both the first and the second questions examine students' idea about food making in plants, the process of food making in plants (materials for making food, process and products of photosynthesis). Here students have an idea about what is photosynthesis means but have no in depth understanding about it because they cannot give further explanations.

In the third question the main concern is how students relate photosynthesis with the global warming. How photosynthesis can help to reduce global warming? This can help to examine students understanding of the concept of photosynthesis and how they relate to the daily life. According to this question students answered that "Photosynthesis can reduce global warming by releasing oxygen to the atmosphere". This response indicated that students can have an idea that plants can produce oxygen during photosynthesis and this is released into the atmosphere but they have no an idea that plants instead can absorb carbon dioxide during photosynthesis. This is one means of reducing the amount of carbon dioxide from the atmosphere and this can help to understand how photosynthesis can decrease global warming.

The last question; what is the purpose of plants to carryout photosynthesis? According to this question the aim is to examine what is the assumption of students that why plants carryout photosynthesis. The students' reflection on this question is; "the purpose of photosynthesis is to produce oxygen". But the main purpose of plants to carry out photosynthesis is for the synthesis of their own food (glucose). Indeed plants can release oxygen during photosynthesis and this oxygen is important for animals including us.

With regards to the first and second questions, some students thought that plants cannot make their own food instead they get their food from the soil instead. That means plants directly feed on soil. In addition, few students thought that plants are non living things. These ideas of students indicate that the concept of photosynthesis is not clear. And for the third and last questions a couple of students reflected that plants can protect global warming by producing air, considered oxygen as wind, and they did not give any response about the purpose of photosynthesis. These responses indicated that students are surprisingly ignorant about how plants produce oxygen. Consequently, after the students' understanding and gaps were examined the interventions were carried out both in experimental group using the CM based teaching and in the control group using traditional teaching method (lecture method).

\section{Intervention in experimental group}

For this group in the first week of the lessons, students explained that "plants have flowers and fruits" but they did not consider flower and fruits are parts of flowering plants. Students also simply consider the parts of plants when they were asked to describe plants without saying something about the question 'what are plants?' After students explanations, a reference CMs which explain about plants and their parts related to their functions were given Figures 2 and 3, respectively. Students could identify the main concepts related to plants by examining the given reference CMs and understanding about plants. And also they could identify that flowers and fruits are parts of flowering plants from the map.

However, students missed some internal structures of leaves (palisade and spongy mesophylls) and did not recognize in which mesophyll tissue more photosynthesis takes place and why? Therefore, after the students' CMs were examined for the presence of internal structures of leaves and their related functions, a reference $\mathrm{CM}$ was provided for students for cross checking their map (Figure 4) and to understand the internal structures of leaves by observing the relation of concepts from the given reference map (Figure 5). Besides the map attached with the picture that show internal structures of leaves and this was shown for students by using LCD projector. This is more important for students to clearly understand concepts and their relations. 




Figure 2. CM constructed to teach students about plants

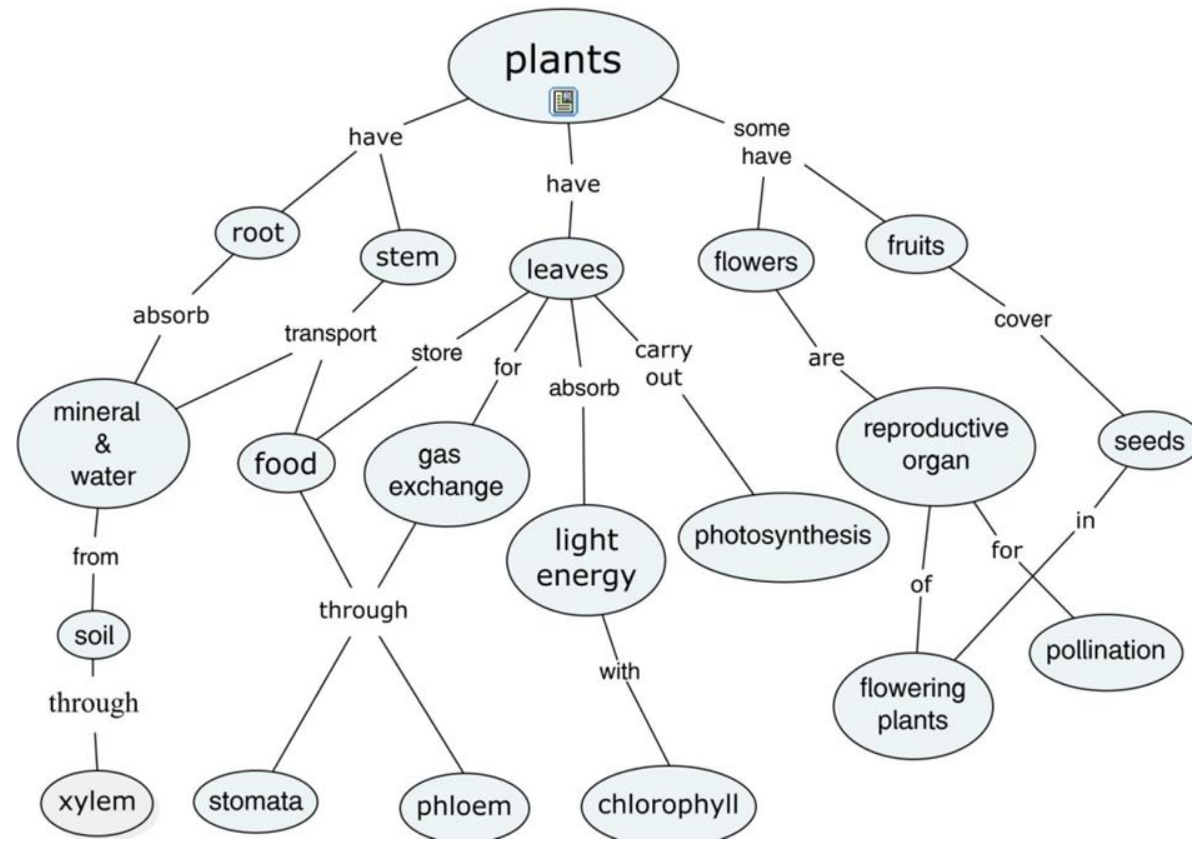

Figure 3. CM constructed to teach students about parts of plants and their functions



Figure 4. Concept map prepared by students 


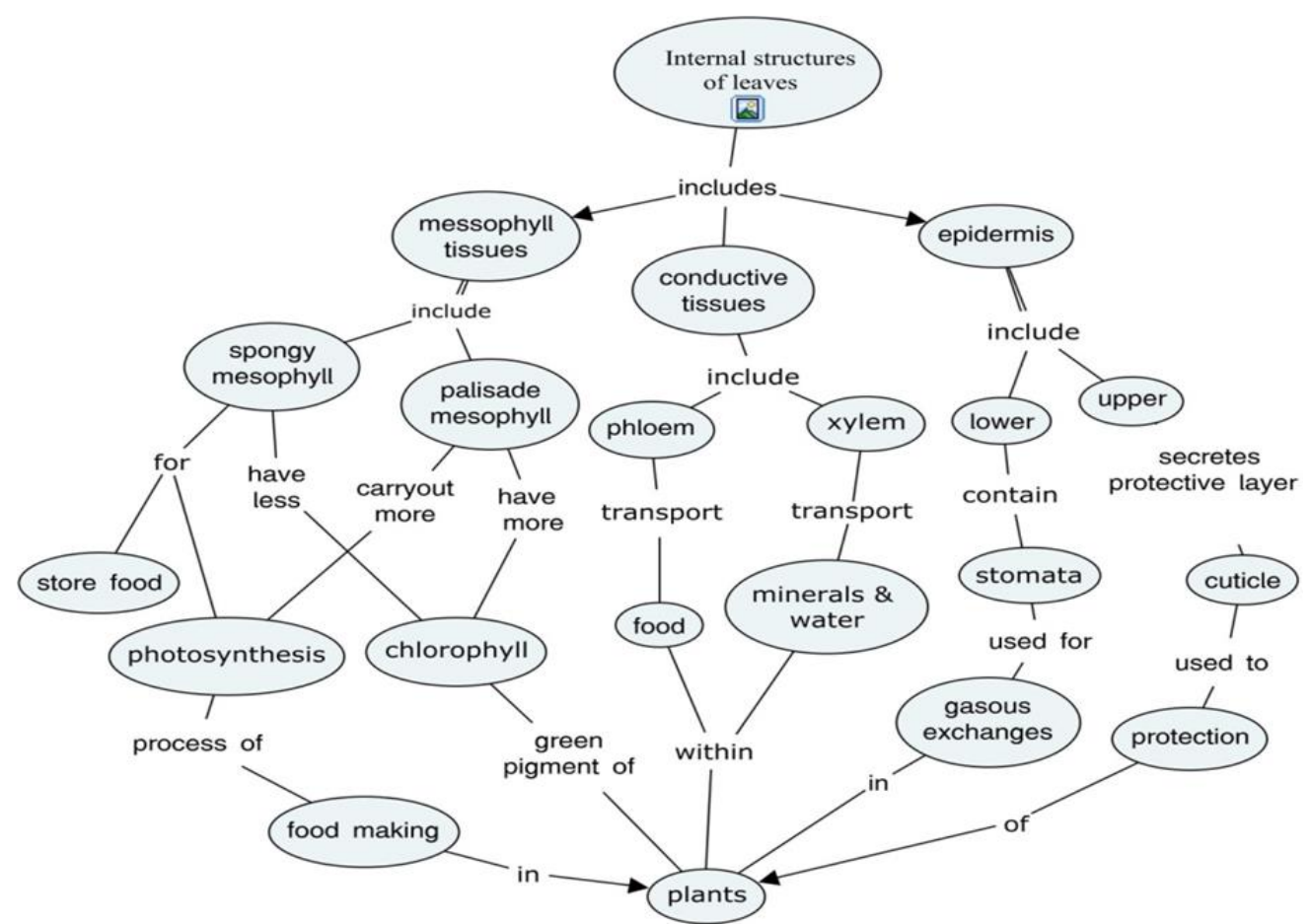

Figure 5. CM constructed to teach students about internal structures of leaves

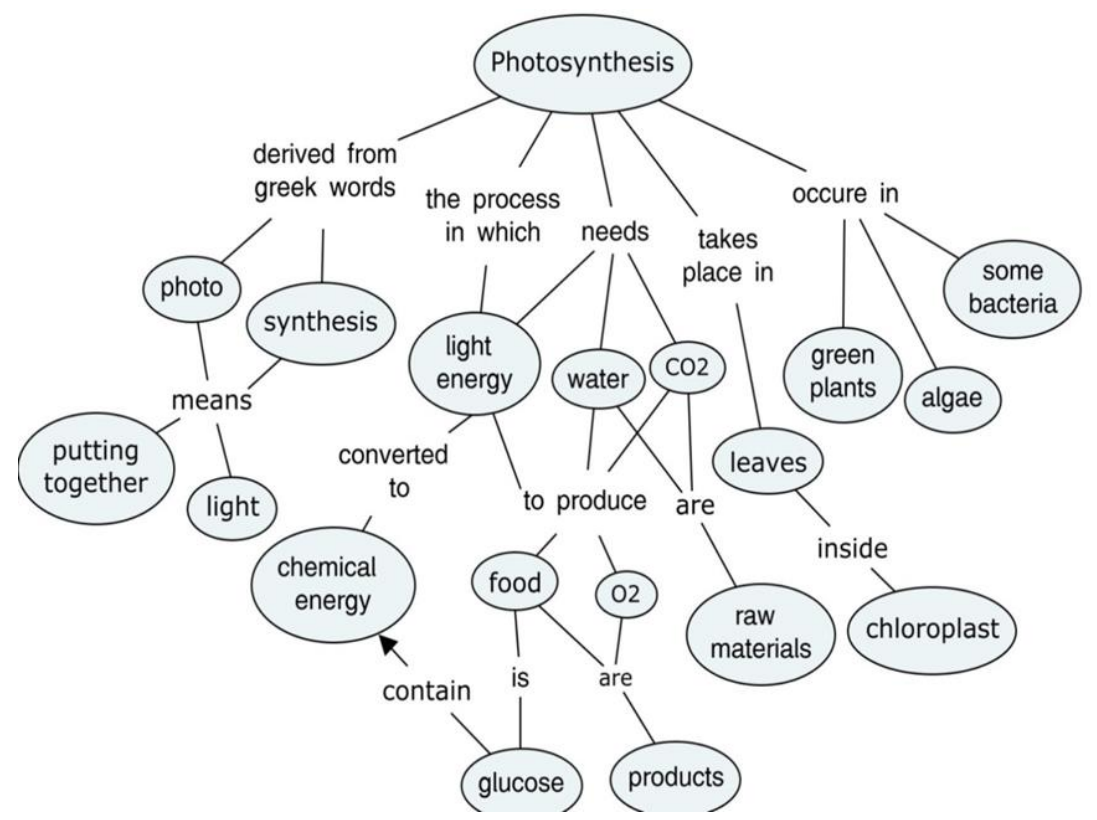

Figure 6. CM constructed to teach students about the concept of photosynthesis

The second and third weeks of intervention has focused on students' skill of CMs construction. The focused questions related to photosynthesis were given and students were been able to construct their own concept maps through reading and identifying concepts from the text, making discussion on concepts, and made relation between and among concepts. The maps constructed are explaining the materials that were taught in the class such as on the concepts of photosynthesis, process and phases of photosynthesis, factors affecting rate of photosynthesis. This improvement of $\mathrm{CM}$ construction by students helped them to think deeply and understand concepts very well while reading, identifying, discussing and relating concepts about photosynthesis. For the focused question "what is photosynthesis?" students could list concepts such as light energy, chemical energy, leaf, photo, light, $\mathrm{CO}_{2}, \mathrm{H}_{2} \mathrm{O}, \mathrm{O}_{2}$, chloroplast, chlorophyll and mesophyll tissues by reading their text and other guide books. They could describe that photosynthesis takes place in leaves, $\mathrm{CO}_{2}, \mathrm{H}_{2} \mathrm{O}$ and lights are raw materials for photosynthesis. They were also able to indicate arrows correctly by relating concepts. After students' understanding and misunderstanding were identified, computer-assisted reference $\mathrm{CMs}$ were given and described concepts related to photosynthesis to summarize the lesson (Figures 6 and 7). 


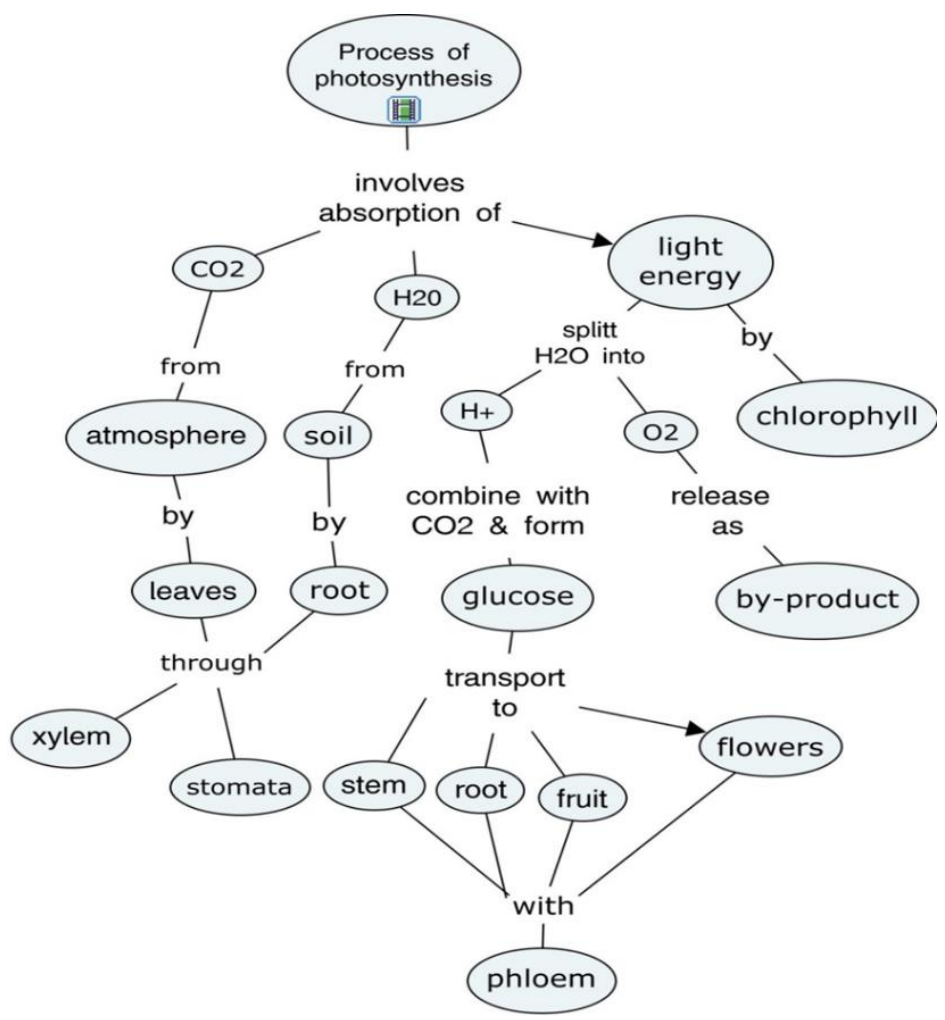

Figure 7. CM constructed to teach students about the process of photosynthesis



Figure 8. CM constructed to teach students about the concept of photosynthesis

Students were also examined on their understanding about the phases of photosynthesis, light and dark reaction. However, as their CM indicated dark reaction occurs during dark time which is a misunderstanding about dark reaction because dark reaction (lightindependent) is a process that takes place in the absence of light. And also students did not differentiate the specific places of chloroplast where light dependent and light independent reactions take place. They simply assumed that both dark and light reactions take place in the chloroplast Figure 8. But light independent reaction takes place in stroma and light dependent reaction takes place in thylakoid membranes of chloroplasts.

After their understanding and misunderstanding on the phases of photosynthesis were examined, a reference $\mathrm{CM}$ on the phases of photosynthesis was provided (Figure 9) and explained for them.

Students in experimental group were also allowed to do an experiment to see the effect of light on plants after concepts about the effect of light on plants are explained. Here students brought two similar germinating plants and put one plant in light near the window and the other plant in dark condition in the laboratory. After one day 


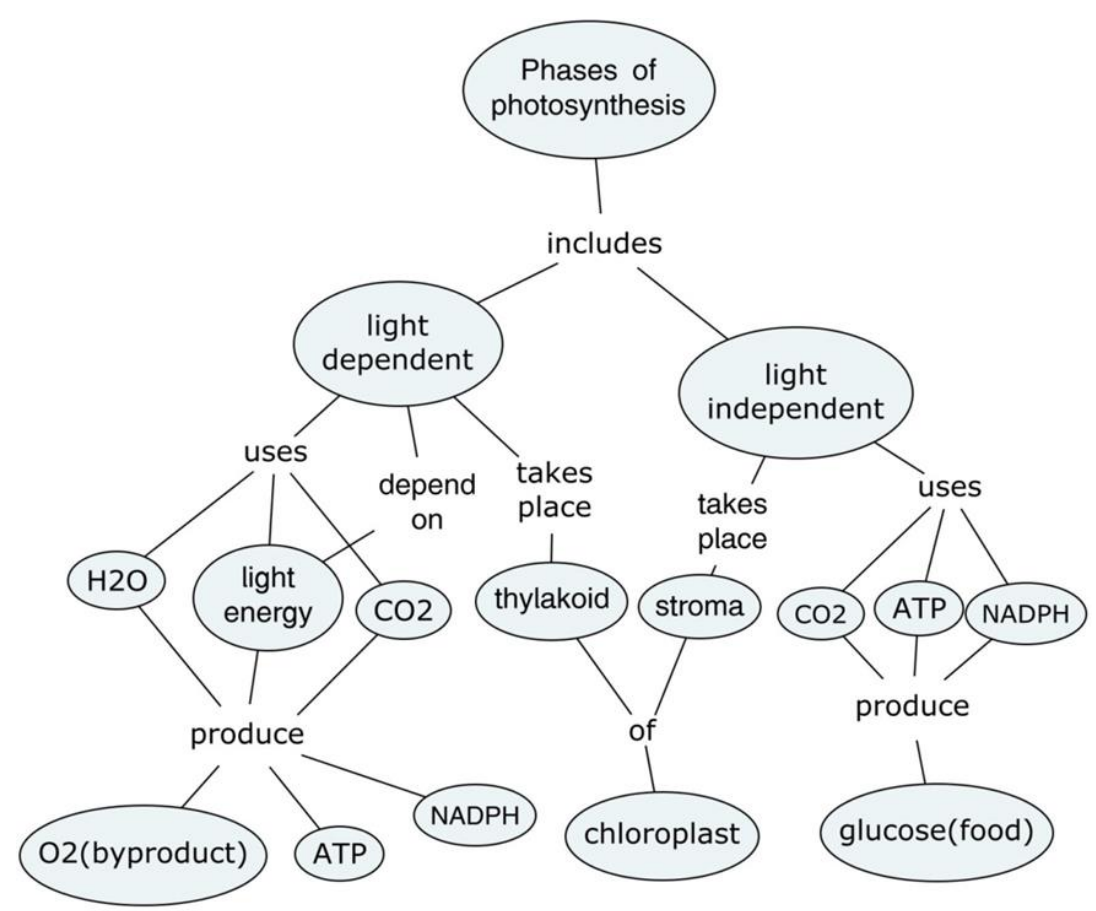

Figure 9. CM constructed to teach students about phases of photosynthesis

students observed the two plants in different light condition and explained their observation as; "a plant that was placed in the dark place became yellow and wilted because it lacks light to make its food whereas a plant placed near the window got light and carried out photosynthesis and became green".

After the topic photosynthesis was completed at the end of all interventions, students in the experimental group were asked to construct $\mathrm{CM}$ that can show what they have learned and understood about photosynthesis. Students have indicated most groups of students were able to list and relate concepts about photosynthesis. However, two groups of students could not use link words; they simply listed and connected some of the concepts of photosynthesis. They lack words to link concepts. Other two groups of students constructed their map by enclosing both the concepts and link words within circles. Then after students understanding and misunderstanding on the concept of photosynthesis and related topics was examined based on the concepts they had put on their CMs, a reference $\mathrm{CM}$ was given to describe almost all concepts related to the topic photosynthesis. Then students cross-checked their maps with the given map, identified the concepts related to photosynthesis. Students used the map for their study of the topic photosynthesis in preparing for the post-test and to understand the main concepts related to photosynthesis.

\section{Result from post-informal assessment questions}

After each intervention informal assessment questions were posted for both groups of students in the classroom to examine their understanding. The responses of the students were obtained by the teacher researcher. Students' response to post- informal assessment questions (after intervention) in the experimental group on the questions were "plants use carbon dioxide and water as raw materials and absorb light by their chlorophyll for making their own food; light energy used to break water in to hydrogen and oxygen, hydrogen and carbon dioxide together form glucose (food of plant) (wana mirt) but oxygen is a by-product (terefe mirt) that is simply released to the environment and used for us and other animals for respiration. Chemical reaction is:

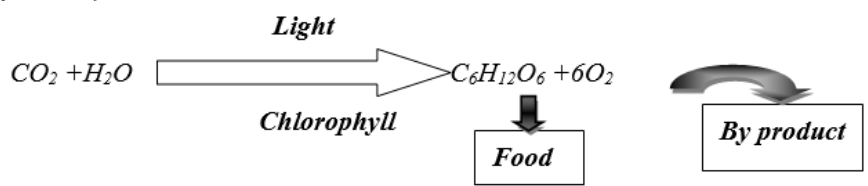

"The concept of photosynthesis contains two subconcepts come from Greek "photo" (light) and "synthesis" (making) and this concept indicates process of making food using light energy by photosynthetic organisms. Plants are important to prevent air pollution and global warming by reducing the amount of carbon dioxide in the air and increase oxygen during photosynthesis. Besides to this, there were some students who have still a misunderstanding on the concept of photosynthesis even after interventions. For example some of them explained that "plants used water directly from rain and plants directly used soils during photosynthesis. This misunderstanding was came as a result of some gaps on the intervention process; for example shortage of intervention time, lack of technological resources to practice students on computer based $\mathrm{CM}$ activities during intervention and frustration of few students about CM method. 
Unlike the experimental group, the control group students were exposed with traditional teaching (lecture) method. The informal assessment was applied the same way as experimental group and nearly the same misunderstanding was identified on students' response before intervention. However, after interventions, students in this group slightly eliminate their misunderstanding and show an improvement in their understanding on the informal assessment questions about photosynthesis. Their responses on post-informal assessment questions were; "plants can make their own food using water, carbon dioxide, light and chlorophyll by the process of photosynthesis, so photosynthesis is the process of making food by green plants. Plants are important to reduce global warming by using carbon dioxide from the atmosphere and releasing oxygen to the atmosphere; by this mechanism they can regulate the environmental condition. According to these students who were taught with traditional based teaching method were able to remediate their misunderstanding they held before intervention to some extent. But they are not reasonable for their idea and still they have some gaps on their understanding on concepts than those who were taught with concept mapping teaching method.

Generally based on the result obtained from informal assessment questions, most of the students in experimental group could give better explanation for the informal assessment questions than those who taught with teacher-centered method after each intervention. This is due to the effect of CM based method on students understanding.

\section{Result from Classroom Observation}

Students of the experimental group, after they were familiar with the CM methods, have shown high degree of participation in the lessons through (1) discussion on the focused questions that were given during each lesson of photosynthesis, (2) identifying the main concepts from the texts, (3) involving in concept mapping activities in each lesson, and (4) presenting their map by describing on the blackboard.

Generally, CM method made students to be more active in their learning and understanding of the concepts especially when they have been participated in concept mapping activities through identifying and relating concepts. And students also commented that:

"CM based teaching method helped us to learn concepts easily in a visual form and this enabled us to understand the concepts of photosynthesis". However, some students commented that "the method is good but we sometimes faced with a shortage of link words to make a relationship between the given concepts while constructing CM".

On the other hand, the passive traditional teaching approach has demanded students to accept the information at face value without questioning or discussing its merits or fallibilities and they were learnt concepts in text form. Thus, this method was found to be ineffective in facilitating students understanding of concepts and their learning process.

\section{DISCUSSION}

This study was conducted on grade eight students to see the effectiveness of concept mapping based teaching strategy on developing of conceptual understanding on the concept of photosynthesis. The pre-test results showed approximately equal mean scores of experimental and control groups and the mean scores difference between the two groups is not statistically significant. These results suggested that the two groups of students have equivalent understanding and prior knowledge on the concept of photosynthesis, and they were suitable for the quasi-experimental study. On the contrary, both groups of students scored a different posttest results from their pretest after intervention. This is because students in both groups were taught the concept of photosynthesis with different instructional methods. However, as the result of the post-test indicated the mean scores of post-test in experimental group were higher than the scores of the pre-test which confirms the trend that students taught with CM method develop better conceptual understanding than those taught with traditional lecture method. This is because students were motivated with CM activities and more opportunities were given to them to construct $\mathrm{CM}$ during the learning process.

In the CM based teaching and learning method students were actively involved in the learning process through identifying main concepts of the topic from the text, involving in the discussion on the concepts, making connections between concepts by constructing their own CMs. During such learning condition, students became active and interactive in their learning, think deeply about concepts during their discussion and used their prior knowledge. These opportunities enabled students to capture and retained more concepts in their cognitive structure, to have better performance on the tests and to have better understanding of photosynthesis concepts. This result is consistent with the ideas of Dent (2011) who described that CM method is a facilitating strategy for meaningful learning and conceptualization. In CM based teaching method, students' focus on concept learning that is the basis for the construction of knowledge and comprehension in any area.

The majority of students during the pre-test had misunderstanding on the concept of photosynthesis. For example, during pre-test, students had misconception on the raw materials and products of photosynthesis, purpose of photosynthesis, place where photosynthesis takes place and why plants are called autotrophs (producers). But after treatment students in the experimental group were able to understand the 
concepts, remediate their misunderstandings and performed better in the post-test than students in control group. This is in line with Cheema \& Mirza, (2013) who revealed the presence of more valid science concepts and fewer misconceptions of CM instructed students than traditionally taught students on general science lessons of grade seven students. However, Reeves (2015) described that traditional teaching- learning method enforces students to learn through memorization and recitation techniques instead of developing their critical thinking, problem solving, conceptual understanding and decision making skills. In traditional teaching method students easily forget the concepts from their mind because they do not understand the meaning and the relationship between and among concepts. According to Shamsudin, (2014) traditional teaching method mostly uses chalk and talk technique, teachers write notes on the black board and students just copy on their notebook and this lead an overloading of information for students.

Regarding students' ability of relating concepts through constructing their own CMs, the present study shows that, most students taught with CM method were able to relate concepts related to photosynthesis during and after the intervention. They could identify the main concepts under the sub-topics of photosynthesis, made relationship between concepts and constructed meaning by themselves. The result of this concept mapping activities is similar to Safdar et al. (2012) in which concept mapping activities enabled students to relate and show the connection of concepts and synthesis of meaning. Hence, CM method fits with constructivist ideas in which students relate concepts and make meanings by their own. This again is supported by Jena, (2012) who stated that CM method is a constructivist approach because it posits students in a discovery of knowledge and enhances meaningful learning in science education.

Students, when taught with CM method, are very keen to interact with the teaching resources such as textbooks and other biology guide books, teaching model "real plant", slide pictures such as internal structures of leaves, and concept maps of photosynthesis as well as with their note book. These interactions of students with such materials helped them to enhance their learning, understanding, performance and their interaction among themselves. This active interaction of students in the learning process led them to develop an independent learning, to construct their own understanding of how the concepts are related, and to develop collaborative learning environment. In CM based teaching method students interacted particularly with concepts and CMs constructed on each topic of the lesson, such interaction enabled them to grasp main concepts of the topic and to understand relationship between the main concepts. This result is in line with Stoica et al, (2011) that stated students interacting with
CMs are better to pay attention to the meaning and relationship between concepts.

\section{CONCLUSION AND IMPLICATIONS}

This study was conducted to understand the effectiveness of CM method on grade eight students' conceptual understanding of photosynthesis concepts. The finding of this study indicated that students taught with CM method had better conceptual understanding and learning of photosynthesis concepts, and they retained what they have learnt during intervention than those who were taught using lecture method. Teachers focus on making connections between concepts and foster new understanding in students by allowing, inspiring and guiding their students on their learning path. Thus, it is quite advantageous to put students in situations that might challenge their previous conceptions and creating contradictions to encourage them on discovery path for their individual efforts or engage in discussion with their peers, teacher or elders. Constructivist teaching helps students to achieve desirable educational goals, it is therefore important for teachers to emphasize on a constructivist teaching practice. This implies that constructivist approach has a paramount role to help students develop their conceptual understanding on various disciplines.

\section{LIMITATIONS AND FUTURE RECOMMENDATIONS}

Based on the finding of this study there are some challenges that constrain this study include shortage of intervention time, lack of computer desk tops to train learners about how to construct concept maps using concept map tools computer software, lack of students computer skill, language problem in some students to make relationship between concepts during concept mapping activities, absenteeism of students from the class during intervention, large class size and lack of white board to construct concept map during intervention period. However, this does not mean that these limitations persist and destroy the ideal conditions of the intervention because the researcher used different alternatives to address the issues. It is recommended that the study be completed in other content areas to determine how concept maps can be used to monitor students' knowledge structure of different types of content.

\section{ACKNOWLEDGEMENTS}

This work was supported by the BDU-NORHED Project [grant code: QZA 0483 ETH-16/0029].

\section{REFERENCES}

Adlaon, R. (2012). Assessing the Effectiveness of CM as instructional tool in High School Biology 
(Unpublished Master's Thesis). Louisiana State University, United States.

Ajaja, O. (2011). Which way do we go in the teaching of biology? Concept mapping, cooperative learning or learning cycle? International Journal of Science and Technology Education Research, 4(2), 18-29. https: / / doi.org/10.5897/IJSTER12.008

Asan, A. (2007). International Forum of Educational Technology \& Society Concept Mapping in Science Class. Journal of Educational Technology and Society, 10(1), 186-195. Retrieved from https://citeseerx. ist.psu.edu/viewdoc/download?doi=10.1.1.111.60 97\&rep=rep $1 \&$ type $=$ pdf

Ausubel, D. (2011). Meaningful learning: From the classical to critical review. Journal of General Psychology, 1(51), 1-15. http://www.if.ufrgs.br/ asr/artigos/Artigo_ID1/v1_n1_a2011.pdf

Aziz, T., \& Rahman, A. (2014). Effect of Concept Mapping Strategy on Students' Achievement in Science at Secondary Level. https://researchgate.net/ publication/281848894

Bahar, A. (2010). Revising learning difficulties in biology. Journal of Biological Research, 33(2), 84-86. https:/ / doi.org/10.1080/00219266.1999.9655648

Birbili, M., \& Lin, H. (2001). Mapping Knowledge: Concept Maps in Early Childhood Education. Journal of Interactive Learning Research, 8(3-4), 289. 308.

https:/ / files.eric.ed.gov/fulltext/EJ1084931.pdf

Cheema, A., \& Mirza, M. (2013). Effect of Concept Mapping on Students' Academic Achievement. Journal of Research and Reflections in Education, 7(2), 125-132. Retrieved from https:/ / www.information tamers.com/PDF/Effect_of_Concept_Mapping_O n_Students $\%$ e2\%80\%99_Academic_Achievement. pdf

Çimer, A. (2012). What makes biology learning difficult and effective: Students views. Educational Research and Reviews, 7(3), 61-71. https://doi.org/10.5897/ ERR11.205

Cook, L. J. (2017). Using Concept Maps to Monitor Knowledge Structure Changes in a Science Classroom. Dissertations. 3139. https://scholarworks.wmich. edu/dissertations/3139

Csete, M. E. Doyle, J. C. (2002). Reverse Engineering of Biological Complexity. Science, 295(5560), 16641669. https:/ / doi.org/10.1126/science.1069981

Darmofal, D., Soderholm, D., \& Brodeur, D. (2002). Using concept maps and concept questions to enhance conceptual understanding. Journal of the Harvard- Danforth Center, 1(3), 3-6. https:/ / doi.org/10.1109/FIE.2002.1157954

Dimec, D. S., \& Strgar, J. (2017). Scientific Conceptions of Photosynthesis among Primary School Pupils and Student Teachers of Biology. International Journal of
Science Education, 7(1), 49-68. Retrieved from https: / / files.eric.ed.gov/ fulltext/EJ1137843.pdf

Fauzi, A., \& Mitalistiani, M. (2018). Highschool Biology topics that perceived difficult by undergraduate students. Didaktika Biologi: Jurnal Penelitian Pendidikan Biologi, 2(2), 73-84. https://doi.org/ 10.32502/dikbio.v2i2.1242

Galvin, E., Simmie, G., \& Grady, A. (2015). Identification of Misconceptions in the Teaching of Biology: A Pedagogical Cycle of Recognition, Reduction and Removal. Journal of Science Teacher Education, 8(2), 18. https:/ / doi.org/10.3968/6519

Irez, S., \& Han, Ç. (2011). Utilizing kuhnian lenses for a better understanding of the meaning of, and resistance to, educational change. International Journal of Environmental and Science Education, 6(3), 251-266. Retrieved from https://files.eric.ed.gov/ fulltext/EJ959419.pdf

Jacobs-Lawson, J., \& Hershey, D. (2002). Concept maps as an assessment tool in psychology courses. Journal of Methods and Techniques, 29(1), 25-29. https:/ / doi.org/10.1207/S15328023TOP2901_06

Jena, A. (2012). Does constructivist approach applicable through concept maps to achieve meaningful learning in Science? Journal of Science Learning and Teaching, 13 (1),1. https://www.eduhk.hk/apfslt/ download/v13_issue1_files/jena.pdf

Jia, Q. (2010). Abrief study on the implication of constructivism teaching theory on classroom teaching reform in basic education. Journal of educational research, 3(2), 197-199. Retrieved from https: / / files.eric.ed.gov/ fulltext/EJ1066095.pdf

Jibrin, A., \& Zayum, D. (2012). Effectiveness of Concept mapping Strategy on Accadenic Achievement of Senior secondary school students in Genetics. Journal of Science, Technology and Education, 1(1), 153.

Kinchin, I. (2001).If the use of concept mapping is so helpful to learning biology, why are not we all doing it? In International Journal of Science Education, 23(12), 1257-1269. https:/ / doi.org/10.1080/095006 90010025058

Kinchin, I., Hay, D., \& Adams, A. (2000). How a qualitative approach to concept map analysis can be used to aid learning by illustrating patterns of conceptual development. Educational Research, 42(1), 43-57. https://doi.org/10.1080/001318800 363908

Kokkonen, T. (2017). Concepts and concept learning in physics (Unpublished doectoral Disertation). University of Helsinki, Helsinki. Retrieved from https://www.semanticscholar.org/paper/CONC EPTS-AND-CONCEPT-LEARNING-IN-PHYSICSKokkonen/d236fc9493c983a10368b7439a6e02ce49c f64fb 
Marmaroti, P., \& Galanopoulou, D. (2006). Pupils' unedrstanding of photosynthesis. International Journal of Science Education, 28(4), 383-403. https:// doi.org/10.1080/09500690500277805

Moreira, M. A. (2011). Why concepts, why meaningful learning, why collaborative activities and why concept maps? Meaningful Learning Review, 1(3), 111. Retrieved from https://www.if.ufrgs.br/ $\sim$ moreira/v1n3a1.pdf

Novak, J., \& Canas, A. (2006). The Origins of the Concept Mapping Tools and the Continuing Evolution of the Tool. Information Visualization, 5, 175-184. https:/ / doi.org/10.1057/ palrave.ivs.9500126

Reeves, E. P. (2015). Teaching to the Test: The Incorporation of Elements of Bar Exam Preparation in Legal Education. Journal of Legal Education, 64(4), 645-655. Retrieved from http://search.ebscohost. com/login.aspx?102974282

Safdar, M., Hussain, A., Shah, I., \& Rifat, Q. (2012). Concept Map: An Instructional Tool to Facilitate Meaningful Learning. European Journal of Educational Research, 3(1), 55-64. https:// doi.org/10.12973/eu-jer.1.1.55

Schmid, R., \& Telaro, G. (2018). Concept mapping as an Instructional Concept Mapping Strategy for High School Biology. Journal of Educational Research, 84(2), 78-85.

https:/ / doi.org/10.1080/00220671.1990.10885996

Schwendimann, B. (2015). Concept Mapping. https:/ / doi.org/10.1007/978-94-007

Sequeira, A. (2012). Introduction to Concepts of Teaching and Learning. National Institute of
Technology Karnataka. https://doi.org/10.2139/ ssrn. 2150166

Shamsudin, N. (2014). Utilization of concept mapping in teaching biodiversity to lower schondary students for science class room. A case Study of Lower Secondary School Students for Science Class Room.

Stoica, I., Moraru, S., \& Miron, C. (2011). Concept maps, a must for the modern teaching-learning process. International Journal of Science Education, 63(2), 567576. https:// pdfs.semanticscholar.org/cf28/b8248 cf118ca8fb7c13f8730ae7ec4961ba1.pdf

Tekkaya C., Özkan Ö., \& Sungur S. (2001). Biology concepts perceived as difficult by Turkish high school students. Journal of Education, 21, 145-150. Retrieved from https://www.scirp.org/(S(351jmb ntvnsjt1aadkposzje))/reference/ReferencesPapers. aspx?RefeenceID $=1714736$

Thurmond, V. A. (2001). The Point of Triangulation. Journal of Nursing Scholarship, 33(3), 253-258. https:/ / doi.org/10.1111/j.1547-5069.2001.00253.x

Trifone, J. D. (2006). To What Extent can Concept Mapping Motivate Students to Take a More Meaningful Approach to Learning Biology ? Science Education Review, 5(4), 1-23. Retrieved from https:/ / eric.ed.gov/ ?id=EJ1057149

Udeani, U., \& Okafor, P. (2012). The Effect of Concept Mapping Instructional Strategy on the Biology Achievement of Senior Secondary School Slow Learners. Journal of Emerging Trends in Educational Research and Policy Studies, 3(2), 137-142. https://journals.co.za/content/sl_jeteraps/3/2/E JC135345

\section{http://www.ejmste.com}

